Research Article

\title{
Self-Assembly of Rice Bran Globulin Fibrils in Electrostatic Screening: Nanostructure and Gels
}

\author{
Lihua Huang, ${ }^{1}$ Yehui Zhang, ${ }^{2}$ and Haibin $\mathrm{Li}^{1}$ \\ ${ }^{1}$ Department of Food, Guangzhou City Polytechnic, Guangzhou 510405, China \\ ${ }^{2}$ Guangdong Key Laboratory of Agricultural Product Processing, Sericulture \& Agri-Food Research Institute GAAS, \\ Guangzhou 510610, China
}

Correspondence should be addressed to Yehui Zhang; zhangyhgx@gmail.com

Received 13 April 2014; Revised 9 July 2014; Accepted 11 July 2014; Published 24 July 2014

Academic Editor: Zhongkui Hong

Copyright (C) 2014 Lihua Huang et al. This is an open access article distributed under the Creative Commons Attribution License, which permits unrestricted use, distribution, and reproduction in any medium, provided the original work is properly cited.

\begin{abstract}
The effects of various ionic strengths and protein concentrations on the fibrils structure and gel properties of rice bran globulin (RBG) at pH 2.0 were investigated using atomic force microscopy (AFM), rheometer, and scanning electron microscope (SEM). AFM images showed the morphology of assembling RBG fibrils from strand beads to becoming branch clustered, when electrostatic repulsive forces attenuated gradually with increasing ionic strength. $\mathrm{NaCl}$ seems to accelerate the kinetics of fibrils formation, resulting in a significant increase in Th $\mathrm{T}$ fluorescence intensity. The increased ionic strengths promote particle size increasing and zeta potential decreasing synchronously. The percolation model $G^{\prime} \sim\left(C-C_{p}\right)^{n}$ be used to calculate theoretical RBG gels concentration at various ionic strengths $(0-500 \mathrm{mM})$, which decreased from $15.17 \pm 0.63$ to $2.26 \pm 0.27 \mathrm{wt} \%$. SEM images exhibited a granular mesh-like gel structure. A more homogenous structure occurred in low ionic strength. This study elucidates properties of RBG fibrils and gels as a bioactive material.
\end{abstract}

\section{Introduction}

Assembling proteins may be as interesting materials in food processing and bionanotechnology, due to the fact that they can remodel structural properties of the system $[1,2]$. Assembling proteins as well as ordered linear aggregates, defined as fibrils, has attracted more attention in recent years. These linear protein fibrils can have a good potential as materials in thickening or gelling, which are widely used in beverage, dessert, and sausage [3-7].

Heating commonly plays a trigger for unfolding protein molecule and caused exposure of inner hydrophobic region. The formation of linear fibrils is primary governed by the equilibrium of intermolecular force, including attractive forces (mainly hydrophobic bonds) among thermally unfolded molecules and repulsive forces [8-10]. Generally, electrostatic repulsive forces attenuated gradually at the high ionic strength, and the preponderant intermolecular hydrophobic forces induced formation of clustered aggregates. Contrarily, at low ionic strength and $\mathrm{pH}$, electrostatic repulsive force predominates the aggregates morphology and formed linear fibrils $[7,11,12]$. At low $\mathrm{pH}$ and low ionic strength, the gels have many advantages, for example, being transparent or semitransparent, being more elastic, and being of low gel critical concentration [13]. It may imply that the length of linear fibrils seems to be less than the wavelength of visible light, leading to the gels being transparent $[14,15]$.

The electrostatic screening affected significantly the structure and physicochemical properties of protein assembly. The effects of electrostatic interactions on the critical protein concentration $\left(C_{p}\right)$ of gel can be investigated by a certain model and a decreasing $C_{p}$ with increasing in a range of ionic strength. Furthermore, the theoretical model can contribute to better understand the special gel structure $[16,17]$.

Rice is one of the earliest cultivated crop species, and human digestive system adapted to these components of rice. There is a growing demand for the use of less allergenic rice protein or rice bran protein as a functional ingredient in food products $[18,19]$. It may be a novel material as clinical nutrition for patients. However, rice protein or rice bran protein 
has poor solubility. The mechanism for the fibril assembly is still not fully understood. The main objective of this work is to confirm RBG fibrils formation at low $\mathrm{pH}$ and various ionic strengths and resulted in changes of structure and characteristics of system. Thus, the structural details of RBG fibrils are propitious to understand the gel physicochemical properties and facilitate application of rice protein-based materials.

\section{Materials and Methods}

Fresh rice bran was purchased from The Rice Research Institute of Guangdong Academy of Agricultural Sciences, Guangzhou, China. Other chemicals applied in the work were of chemical grade. All solutions were prepared with deionized water.

2.1. Preparation of RBG Fibrils. The purified rice bran globulin was prepared according to the method described by Chanput from the defatted rice bran flour and with slight modifications [20]. The $2.0 \mathrm{wt} \% \mathrm{RBG}$ solutions at various ionic strength $(0,100,200,300,400$, and $500 \mathrm{mM})$ were set to $\mathrm{pH} 2.0$, and then were put into closed test tubes. These tubes were heated at $90^{\circ} \mathrm{C}$ for $2 \mathrm{~h}$, followed by rapid cooling to ice water for further experiments.

2.2. Samples Preparation for AFM. RBG samples dispersions were diluted to $25 \mu \mathrm{g} / \mathrm{mL}$, and a droplet is spread on a freshly cleaved mica disk and dried overnight. AFM images were captured by using tapping mode. A Dimension 3000 microscope (Digital Instruments-Veeco, Santa Barbara, CA, US) was manipulated by a Nanoscope IIIa controller. 3-5 images for each sample were taken.

2.3. Distribution of Zeta Potential and Particle Sizes. RBG samples dispersions were diluted to $0.50 \mathrm{wt} \%$ and filtered through a $0.45 \mu \mathrm{m}$ membrane (Millipore). Zeta potential and hydrodynamic diameter (particle sizes) were determined by using dynamic light scattering instrument (Zetasizer Nano ZS, Malvern, Worcestershire, UK). Zeta potential and particle sizes were carried out with the instrument specification. Zeta potential was measured using a multipurpose autotitrator (MPT-2, Malvern Instruments, Worcestershire, UK). The titration was set to $\mathrm{pH} 2.0$ with $0.1 \mathrm{~mol} \mathrm{HCl}$ working solution. These samples were measured three times at least.

2.4. Th T Fluorescence Intensity and Kinetics. Add $8 \mathrm{mg}$ Th $\mathrm{T}$ into $10 \mathrm{~mL}$ of phosphate buffer ( $\mathrm{pH} \mathrm{7.0)}$ containing $150 \mathrm{mM}$ $\mathrm{NaCl}$ and fully shake for a certain number of minutes [21]. The dispersion was filtered with a $0.2 \mu \mathrm{m}$ syringe filter to remove undissolved Thioflavin $\mathrm{T}$ (Th $\mathrm{T})$. This stock solution was stored at $4^{\circ} \mathrm{C}$ and covered with foil. The stock solution was diluted 50 times for preparing the working solution. The fluorescence spectra of the mixtures were measured using a fluorescence spectrophotometer (F-4500, Hitachi, Japan). The excited wavelength was set at $460 \mathrm{~nm}$ (slit width = $10 \mathrm{~nm}$ ) and the emission wavelength from 470 to $500 \mathrm{~nm}$, (slit width $=5 \mathrm{~nm}$ ), scanning spectra were obtained from 450 to $600 \mathrm{~nm}$ and scanning speed of $900 \mathrm{~nm} / \mathrm{min}$. The fluorescence intensity peak was determined at $484 \mathrm{~nm}$. The fluorescence spectrum of the Th $\mathrm{T}$ working solution was subtracted from the fluorescence spectra of the samples to correct the background signal.

The kinetics of RBG in pH 2.0 and various ionic strength solutions were calculated using one phase exponential association equation:

$$
y=y_{\max }\left[1-e^{\left(k_{1} * t\right)}\right]
$$

where $y$ is the relative fluorescence intensity, $y_{\max }$ is the maximum plateau of fluorescence intensity, $t$ is time, and $k$ is the process constant. This equation depicts the sequence association kinetics of the interaction between fibrils and Th T.

2.5. Percolation Model for Gel System. The percolation model as one of theoretical models for elasticity of gels is based on percolation concept [11]. The percolation model is as follows:

$$
G^{\prime} \sim\left(C-C_{p}\right)^{n}
$$

where $G^{\prime}$ is elastic moduli, $C$ is the native protein concentration, $C_{p}$ is the critical threshold concentration, and $n$ is a scaling exponent depending on the Hamiltonian of the system. This equation determines $C_{p}$ and $n$ as a function of ionic strength by using a fitting procedure.

The $G^{\prime}$ was measured using parallel stainless steel plates ( $d=40 \mathrm{~mm}$ ) which were carried out in a rheometer $(1500 \mathrm{ex}$, AR, US). About $1.5 \mathrm{~mL}$ RBG samples (2.0-20.0 wt\%) were placed into parallel plates and sealed with mineral oil. The heating-cooling cycle program was set at $90^{\circ} \mathrm{C}$ for $2 \mathrm{~h}$ and followed by cooling to $25^{\circ} \mathrm{C}$ at $-2^{\circ} \mathrm{C} / \mathrm{min}$.

\section{Results and Discussion}

3.1. The Morphology of RBG Fibrils at Various Ionic Strengths. The RBG can form linear fibrillar aggregates at a range of heating time and $\mathrm{pH}$ 2.0. Figure 1 shows AFM height images of self-assembly RBG fibrils from $0 \mathrm{mM}$ to $500 \mathrm{mM} \mathrm{NaCl}$ concentrations. In low $\mathrm{NaCl}$ concentrations (below $200 \mathrm{mM}$ ), linear fibrils revealed clearly that the fibrils contour length is about $100-200 \mathrm{~nm}$ and width is around $20 \mathrm{~nm}$. However, at $300 \mathrm{mM}$ or higher $\mathrm{NaCl}$ concentrations, the fibrils become branch clustered gradually, and even the curly fibrils become more prominent in $500 \mathrm{mM} \mathrm{NaCl}$ concentration. The fibrils contour length increased with increasing ionic strength. The contour length of $500 \mathrm{~nm}$ or above fibrils can be observed universally in the higher ionic strength. Figure 1 shows that the fibrils thickness seems to decrease with increasing ionic strengths. The contrasting colors of fibrils height faded gradually at $400 \mathrm{~nm}$ and $500 \mathrm{~nm} \mathrm{NaCl}$ concentration. The thicknesses of the fibrils at various ionic strengths coincided within the experimental error. In the absence of additional $\mathrm{NaCl}$, the fibrils population is more uniform, in spite of the presence of significant length difference between individual fibrils [22].

The morphological difference of the fibrils at various ionic strengths can be attributed to the changes of intermolecular interaction. The electrostatic repulsion among the protein 

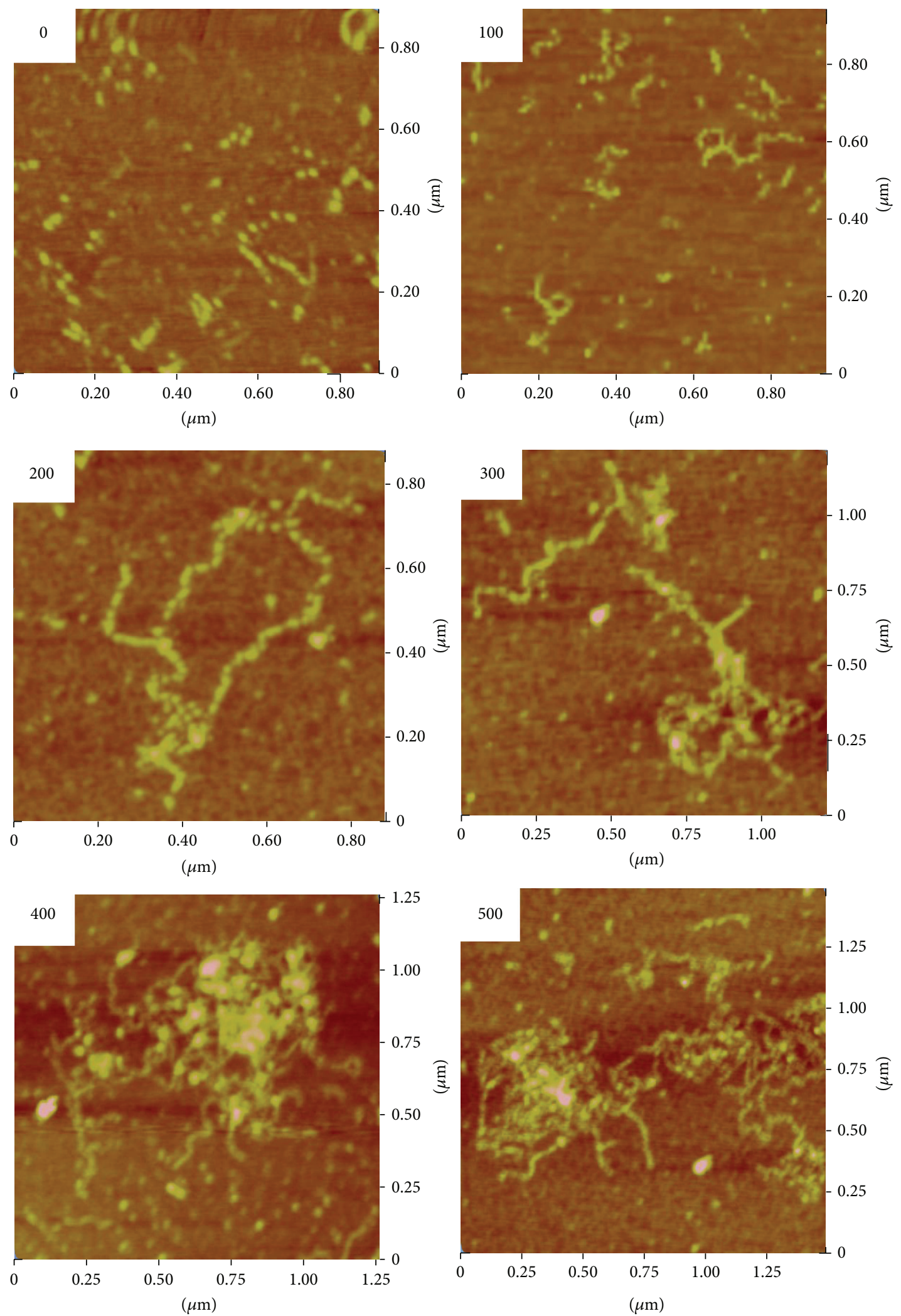

FIGURE 1: Tapping mode AFM photographs of RBG fibrils ( $\mathrm{pH} 2.0$ and heating $2 \mathrm{~h}$ ) at various ionic strengths $(0-500 \mathrm{mM})$. 

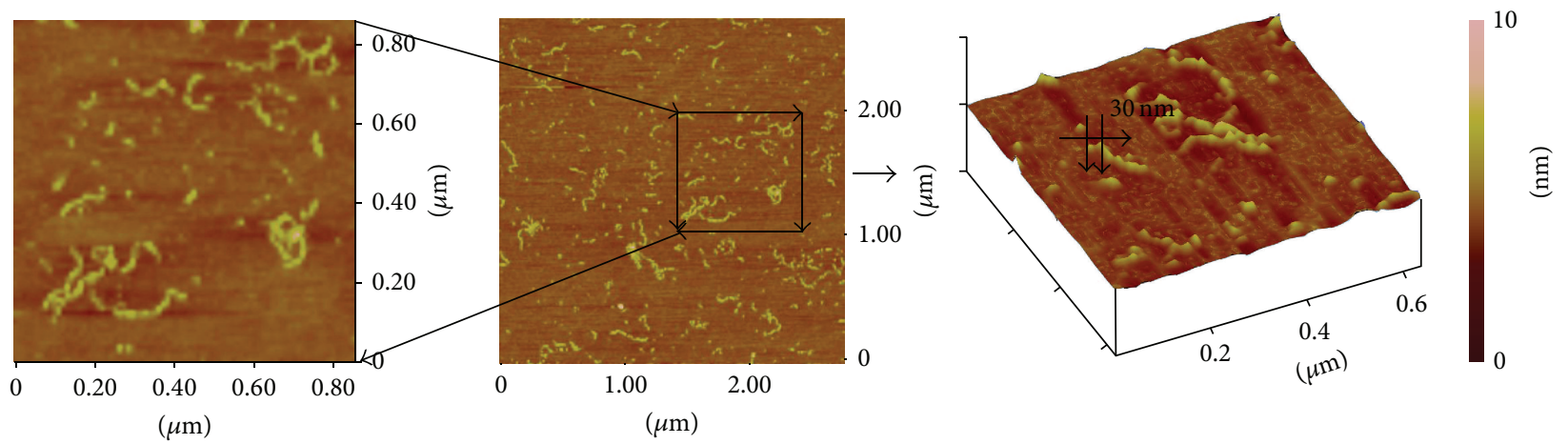

FIGURE 2: Phase photograph of RBG self-assembly into nanofibrils. Enlarged and three-dimensional photograph indicates that the protein undergoes conformational changes.

TABLE 1: The kinetics of Th T-RBG fibrils association in $\mathrm{pH} 2.0$.

\begin{tabular}{lcccccc}
\hline & \multicolumn{5}{c}{ Ionic strength $(\mathrm{mM})$} \\
& 0 & 100 & 200 & 300 & 500 \\
\hline$y_{\max }($ a.u. $)$ & $1233 \pm 19$ & $1352 \pm 31$ & $1378 \pm 25$ & $1423 \pm 17$ & $1507 \pm 38$ \\
$k\left(\mathrm{~min}^{-1}\right)$ & -0.30 & -0.35 & -0.36 & -0.43 & -0.53 & $1586 \pm 23$ \\
$t_{1 / 2}(\mathrm{~min})$ & 2.3 & 2.0 & 1.9 & 1.6 & 1.3 & -0.63 \\
\hline
\end{tabular}

The kinetics of ThT-RBG fibrils association at heating for $120 \mathrm{~min}$ has been fitted using the exponential association equations. $t_{1 / 2}$ is the half time to plateau value.

monomers is an important factor for determining the rate of fibril formation. The electrostatic repulsive forces attenuated gradually with increasing $\mathrm{NaCl}$ concentrations. The nucleation and elongation of protein fibrils are due to active multimolecular reactions and highly depend on ionic strength rather than the reaction between molecules [23, 24]. The result elucidated that increasing ionic strength (or electrostatic screening) promotes the RBG fibrils assembly at $\mathrm{pH}$ 2.0.

Three three-dimensional AFM photographs of the fibrils exhibit the structure with a periodicity around $30 \mathrm{~nm}$ (Figure 2 ). The periodical change among the different fibrils is apparently independent of the ionic strength in the studied range. The periodical structure may be affected by protein type and intermolecular interaction. Similarly, the periodic changes of fibrils had been noticed in soy $\beta$-conglycinin and BSA [17, 25]. Using super sharp tips, lysozyme fibrils can be easily observed to have a helical structure, which is shown in AFM images obviously [26]. The RBG fibrils may be have a similar helical structure. The mechanism of periodical structure changes at various amount of electrostatic screening need to further research.

3.2. The Kinetics of RBG-Th T Fibrils Formation. The fluorescence intensity of native $\mathrm{RBG}$ at $\mathrm{pH} 2.0$ was quite low. Heating is regarded as a trigger for fibrils formation. At $\mathrm{NaCl}$ concentration $(0-500 \mathrm{mM})$, the formed fibrils can bind to Th $\mathrm{T}$, resulting in a significant increase in fluorescence intensity after heating $2 \mathrm{~h}$. Table 1 shows that the increasing $\mathrm{NaCl}$ results in an increase in amount of maximal fluorescence intensity. The electrostatic repulsion is responsible for attenuated $\mathrm{Th} \mathrm{T}$ binding at $\mathrm{pH} 2.0$; higher ionic strength may partially attenuate the effect of electrostatic repulsion.
This observation exhibits that the attenuation of electrostatic repulsion is favorable for RBG fibril assembly.

Th $\mathrm{T}$ does not or only slightly affects the fibrils formation at early stage [27]. In order to optimize the fibrils formation, the assembly kinetics of Th T binding RBG into fibrils at various ionic strengths were investigated. Generally, the Th $\mathrm{T}$ fluorescence intensity is dependent on the $\mathrm{pH}$ value. In the lower $\mathrm{pH}$, it also seems to accelerate the kinetics of ThTbinding [28]. Th $\mathrm{T}$ fluorescence and absorbance are associated with the various ionic strengths. The ionization state of Th $\mathrm{T}$ molecule at various ionic strengths was investigated; absorbance was measured as a function of time (Table 1). Importantly, the effects of various ionic strengths on kinetics of fibrils formation present in a significant difference. A range of $\mathrm{NaCl}$ concentration can accelerate the kinetics of fibril formation and result in a certain extent increase of the amount of fibrils. The process constant $k$ and half time of $t_{1 / 2}$ are decreasing with increasing ionic strength. Sensitivity of the fibrils structures on $\mathrm{NaCl}$ concentrations indicates that a structural difference present in the various degrees of the electrostatic shielding.

3.3. Distribution of Zeta Potential and Particle Sizes. Ionic strength usually plays an essential role in the process of aggregates formation. The differences of morphology, structure, and special conformation of assembly protein are attributed to the degree of the electrostatic shielding at various salt concentrations. Figure 3 shows the differences of electrostatic forces at various ionic strengths. Zeta potential is commonly regarded as an indication for protein suspension stability [29]. The higher absolute values of zeta potential have better stability than that of the lower. At around $\mathrm{pH} 2.0$, the zeta 

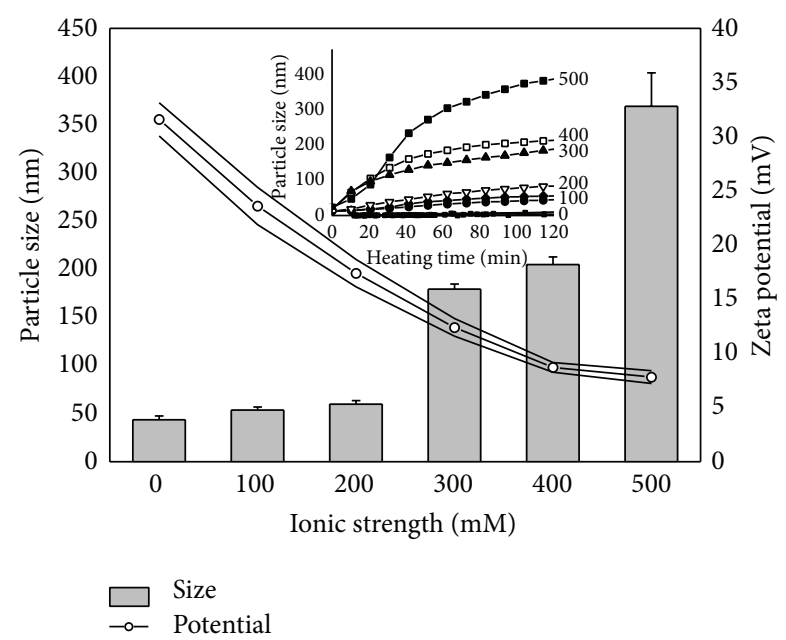

FIGURE 3: Zeta potential and particle sizes of RBG fibrils at various ionic strengths $(0-500 \mathrm{mM})$. (Inset) The kinetic of average particle sizes as a function of RBG fibrils at different heating time (0$120 \mathrm{~min})$.

potential absolute value attenuated with increasing of the ionic strength and results in decrease of electrostatic repulsive forces. Concomitantly, the absolute values decreased from $31.4 \mathrm{mV}$ to $7.9 \mathrm{mV}$. Generally, the formed fibrils have highly net charge (above +20$)$ at low $\mathrm{pH}$ and low ionic strengths (below $200 \mathrm{mM}$ ) [30].

Protein particle sizes and distribution are also affected significantly by various ionic strengths. Figure 3 exhibits that the average particle size of RBG fibrils increased with increasing ionic strength was almost exponential at initial stage, due to the fibrils profile becoming clustered and increasing the volume at high ionic strength. An increase volume of particles is consistent with that of the particle size as determined by dynamic light scattering technique. The particles size increased from $42.31 \pm 2.58 \mathrm{~nm}$ to $419.22 \pm$ $35.17 \mathrm{~nm}$, when the $\mathrm{NaCl}$ concentrations changed from 0 to $500 \mathrm{mM}$. Inset of Figure 3 shows the kinetics of mean particle sizes as a function of RBG fibrils at different heating time $(0-120 \mathrm{~min})$. The presence of $\mathrm{Na}^{+}$and $\mathrm{Cl}^{-}$significantly increased the molecular mass and radius of gyration of aggregates [31]. An important point is the mutual association between protein molecules induced form aggregates easily, when the electrostatic repulsions become weak. Interestingly, the change of Th T fluorescence intensity and particle size is not synchronous. It takes about $40 \mathrm{~min}$ to reach the plateau of particle size, which is an order of magnitude higher than the values of Th $\mathrm{T}$ fluorescence intensity. In the native protein solution, the rice bran protein molecules aggregated together to form larger particles. This maybe increases the value of the protein size and resulted in the detected value of particle size being greater than that of the true value in the initial stage of fibrils formation.

3.4. Fitting with Percolation Models. The elastic modulus $G^{\prime}$ is as a power law according to percolation model $G^{\prime} \sim(C-$ $\left.C_{p}\right)^{n}$, which can use $\left(G^{\prime}\right)^{1 / n}$ versus $C$ and extrapolates these
TABLE 2: The percolation critical concentrations and exponent $n$ at various ionic strengths.

\begin{tabular}{lccc}
\hline Ionic strength $(\mathrm{mM})$ & $R^{2}$ & $n$ & $C_{p}$ \\
\hline 0 & 0.9846 & $1.8 \pm 0.2$ & $15.17 \pm 0.63^{\mathrm{a}}$ \\
100 & 0.9995 & $2.1 \pm 0.1$ & $10.76 \pm 0.34^{\mathrm{b}}$ \\
200 & 0.9984 & $2.1 \pm 0.2$ & $6.33 \pm 0.53^{\mathrm{c}}$ \\
300 & 0.9958 & $1.9 \pm 0.1$ & $5.81 \pm 0.20^{\mathrm{c}}$ \\
400 & 0.9889 & $2.0 \pm 0.3$ & $4.52 \pm 0.59^{\mathrm{d}}$ \\
500 & 0.9946 & $1.9 \pm 0.2$ & $2.26 \pm 0.27^{\mathrm{e}}$ \\
\hline
\end{tabular}

The data in the table are presented as mean \pm standard deviation; the letter shows significant difference.

plots to $\left(G^{\prime}\right)^{1 / n}=0$. The modulus $G^{\prime}$ has an explicit positive correlation to the gels strengths. $G^{\prime}$ of gels can be obtained in a linear regime through strain sweep, where the value is independent of the strain amplitude (data not shown). Figure 4(a) shows the $G^{\prime}$ of RBG gels in $300 \mathrm{mM} \mathrm{NaCl}$ concentration and protein concentration. A point of interest noteworthy is that the values of $G^{\prime}$ in same ionic strength seem to exhibit a strong linear correlation in logarithmic axes.

The fitting procedure relies on the independency of the exponent $n$. In fitting procedure, $\left(G^{\prime}\right)^{1 / n}$ being extrapolated to zero should yield the same $C_{p}$. The fit linear must all intersect the concentration axis at the same value. When assumed $n$ value is close to the actual value, the $R$ is more closed to 1. These points have goodness of fit with line (Figure 4(b)). In the calculation process, the ranges of exponential $n$ were assumed to be from 1.5 to 4.0. Afterwards, these points will be on a straight line when the $n$ reaches the highest value. The theoretical value of $C_{p}$ could be calculated from percolation model $G^{\prime} \sim\left(C-C_{p}\right)^{n}$. The cross point of straight line (the maximum $n$ value) and protein concentration axis is the theoretical $C_{p}$. In this study, the average exponent $n=$ $1.96 \pm 0.19$ for the RBG gels. The $n$ value of gels at the range of percolation model, which assumed an isotropic force between the nearest neighbors on the gels network, and suggested the formation of a homogenous gel network $[32,33]$. The result expounding the exponent $n$ is a function for the gel structure. The average $C_{p}$ and $n$ at various ionic strengths are also listed in Table 2 . The $C_{p}$ of RBG gel successively decreased from $15.17 \pm 0.63 \mathrm{wt} \%$ to $2.26 \pm 0.27 \mathrm{wt} \%$ when ionic strength increased from $0 \mathrm{mM}$ to $500 \mathrm{mM}$.

The critical concentration RBG gels also highly depended upon ionic strength. Generally, the gel can be defined as a fine-stranded or particulate gel. Fine-stranded gels are transparent or semitransparent, whereas the particle gels are turbid or opaque [14]. At low $\mathrm{pH}$ and ionic strength (below $200 \mathrm{mM}$ ), RBG gel reveals a semitransparent form, which gradually changed from transparent to turbid, even opaque, with increasing of protein concentration and/or ionic strength.

Hydrophobic interactions, electrostatic repulsive force, and covalent bonds affected the appearance of gel network [34]. Figures 5(a) and 5(b) show AFM images of RBG gels (16.0 wt\%) at ionic strength of $100 \mathrm{mM}$ and $500 \mathrm{mM}$. A droplet of sample in critical conditions was dripped on the 


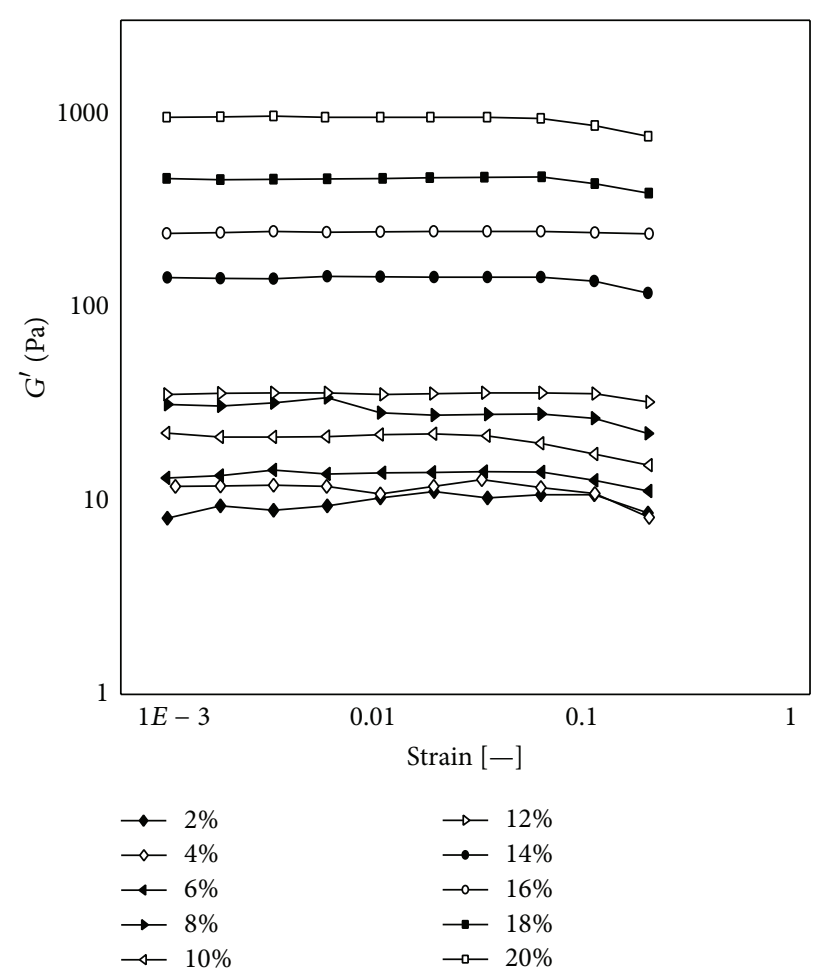

(a)
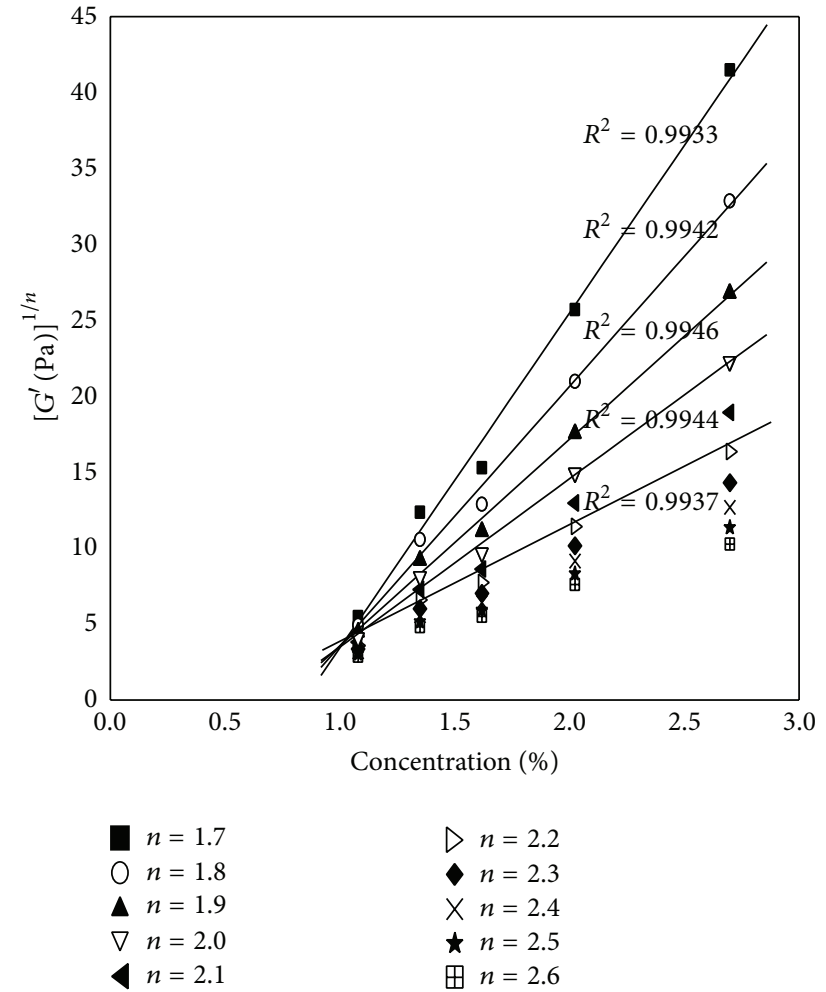

(b)

FIGURE 4: $G^{\prime}$ as a function of strain for RBG gels at $\mathrm{pH}$ 2.0. (a) $G^{\prime}$ versus protein concentration for RBG gels at a certain ionic strength (NaCl, $300 \mathrm{mM})$; (b) $\left[G^{\prime}(\mathrm{Pa}) 1 / n\right]$ as a function of concentration, for $n=1.7,1.8,1.9,2.0,2.1,2.2,2.3,2.4,2.5,2.6,2.7,2.8,2.9,3.0,3.5$, and 4.0 .

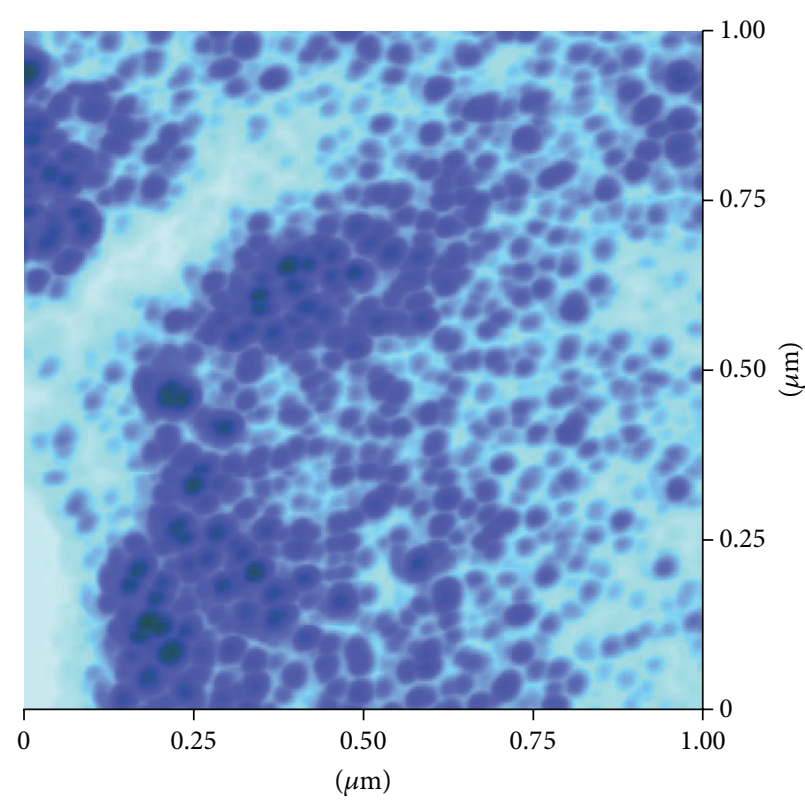

(a)

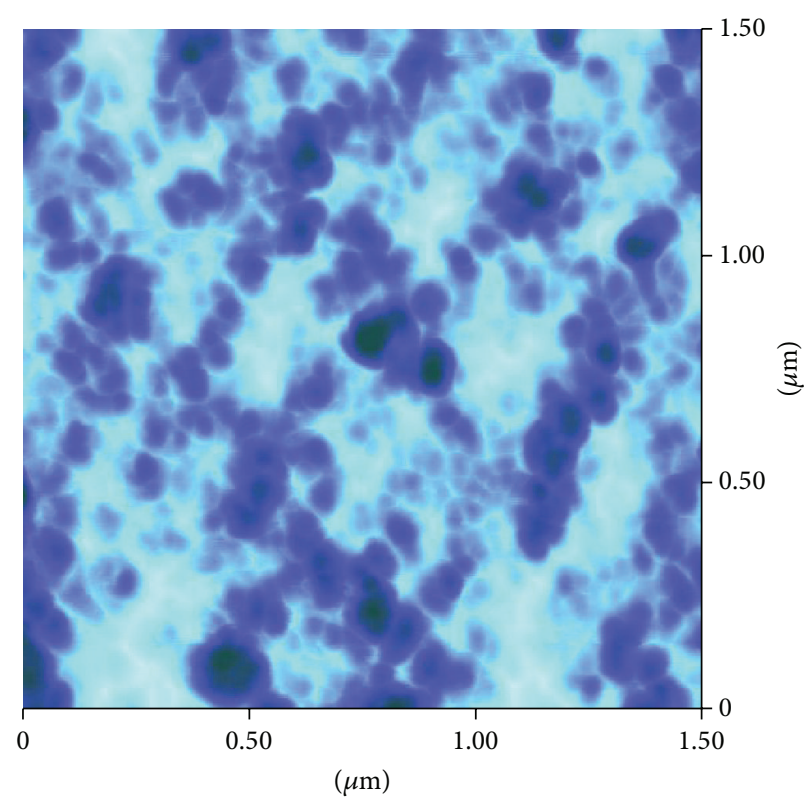

(b)

FIGURE 5: AFM images of RBG gels structure were adjusted for hue for outstanding network. (a) NaCl, $100 \mathrm{mM}$, (b) NaCl, $500 \mathrm{mM}$. 


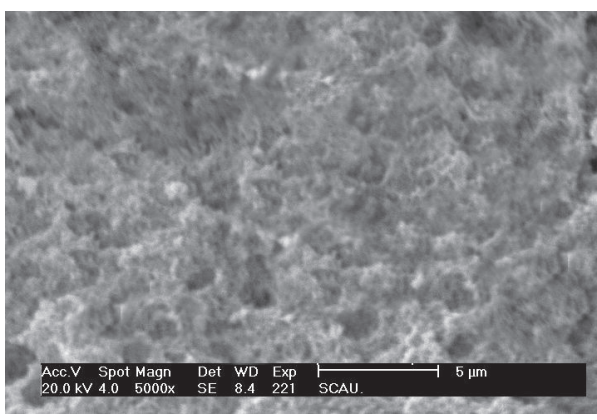

(a)

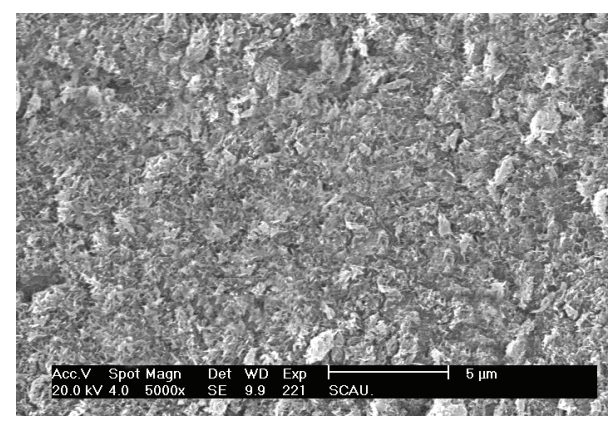

(b)

FIGURE 6: The SEM micrographs of RBG gels at various ionic strengths. (a) NaCl, $100 \mathrm{mM}$, (b) NaCl, $500 \mathrm{mM}$.

surface of mica and then air dried over the night. In order to highlight microscopic structure, the two AFM images were adjusted for hue for network. The images show a granular dense mesh-like structure and intensive cross-linked network. Gel mesh-like structure attribute to molecular interaction at higher electrostatic screening.

Figure 6 shows SEM micrographs of RBG gels at 100 and $500 \mathrm{mM} \mathrm{NaCl}$ concentrations. The two micrographs are all show a granular mesh-like structure. An intensive crosslinked network was observed. Mesh-like structure of gel is attributed to the protein type and intermolecular force. Comparing the difference between $100 \mathrm{mM}$ and $500 \mathrm{mM}$, the latter seems to be composed of larger structures than those of former. This structural heterogeneity is more explored in higher $\mathrm{NaCl}$ concentrations. The micrograph reveals the higher density particle structures present in higher ionic strength. These results in combination with SEM micrographs proved that the fibrils from linear to clustered aggregates with increasing ionic strength. In addition, the structural change is accompanied by an increase in gel strength at equal protein concentration with increasing ionic strength. Effect of various $\mathrm{NaCl}$ concentrations on earlier aggregated processes includes the fibrils formation and properties, which is conducive to understanding the fibrils structure and application of fibrils and gels as soft materials.

\section{Conclusion}

Electrostatic screening affected significantly the formation and characteristics of RBG fibrils. The fibrils reveal linear beads structure and periodic changes at lower ionic strength, whereas the voluble and clustered fibrils are prominent in higher ionic strength. The structure and morphology of fibrils at the initial period plays a key role in gels network and gel strength. The percolation model $G^{\prime} \sim\left(C-C_{p}\right)^{n}$ fit for RBG gels and can calculate RBG gels critical concentrations. The presence of fibrils can modify textural properties of RBG gel system, which are suitable for application as a natural nanoscale gelling material.

\section{Conflict of Interests}

The authors declare that there is no conflict of interests regarding the publication of this paper.

\section{Acknowledgments}

This work is part of the research projects of National Science Foundation of China (NSFC, 31301603), the Guangdong Natural Science Foundation (S2013040013718), the municipal university research projects of Guangzhou (2012A132), and Guangzhou City Polytechnic projects (Ky2013001).

\section{References}

[1] R. V. Lisa, V. Michele, M. D. Christopher, and P. J. K. Tuomas, "A clear view of polymorphism, twist, and chirality in amyloid fibril formation," ACS Nano, vol. 7, no. 12, pp. 10443-10448, 2013.

[2] J. D. Hartgerink, E. Beniash, and S. I. Stupp, "Self-assembly and mineralization of peptide-amphiphile nanofibers," Science, vol. 294, no. 5547, pp. 1684-1688, 2001.

[3] C. Akkermans, A. J. van der Goot, P. Venema, E. van der Linden, and R. M. Boom, "Formation of fibrillar whey protein aggregates: influence of heat and shear treatment, and resulting rheology," Food Hydrocolloids, vol. 22, no. 7, pp. 1315-1325, 2008.

[4] C. Tang, Y. Zhang, Q. Wen, and Q. Huang, "Formation of amyloid fibrils from kidney bean $7 \mathrm{~S}$ globulin (Phaseolin) at $\mathrm{pH}$ 2.0," Journal of Agricultural and Food Chemistry, vol. 58, no. 13, pp. 8061-8068, 2010.

[5] C. Veerman, H. Ruis, L. M. C. Sagis, and E. van der Linden, "Effect of electrostatic interactions on the percolation concentration of fibrillar $\beta$-lactoglobulin gels," Biomacromolecules, vol. 3, no. 4, pp. 869-873, 2002.

[6] H.-L. Zhang, S.-H. Wu, Y. Tao, L.-Q. Zang, and Z.-Q. Su, "Preparation and characterization of water-soluble chitosan nanoparticles as protein delivery system," Journal of Nanomaterials, vol. 2010, Article ID 898910, 5 pages, 2010.

[7] A. E. Marlowe, A. Singh, and Y. G. Yingling, "The effect of point mutations on structure and mechanical properties of collagenlike fibril: a molecular dynamics study," Materials Science and Engineering C, vol. 32, no. 8, pp. 2583-2588, 2012.

[8] S. Fujiwara, F. Matsumoto, and Y. Yonezawa, "Effects of salt concentration on association of the amyloid protofilaments of hen egg white lysozyme studied by time-resolved neutron scattering," Journal of Molecular Biology, vol. 331, no. 1, pp. 21-28, 2003.

[9] A. Farahnaky, H. Askari, M. Majzoobi, and G. Mesbahi, "The impact of concentration, temperature and $\mathrm{pH}$ on dynamic rheology of psyllium gels," Journal of Food Engineering, vol. 100, no. 2, pp. 294-301, 2010.

[10] G. Cheng, V. Castelletto, C. M. Moulton, G. E. Newby, and I. W. Hamley, "Hydrogelation and self-assembly of fmoc-tripeptides: 
unexpected influence of sequence on self-assembled fibril structure, and hydrogel modulus and anisotropy," Langmuir, vol. 26, no. 7, pp. 4990-4998, 2010.

[11] X. Shen, T. Jiao, Q. Zhang et al., "Nanostructures and selfassembly of organogels via benzimidazole/ benzothiazole imide derivatives with different alkyl substituent Chains," Journal of Nanomaterials, vol. 2013, Article ID 409087, 9 pages, 2013.

[12] P. Moritz, H. Ulf, and J. M. Daniel, "Quantitative imaging of the electrostatic field and potential generated by a transmembrane protein pore at subnanometer resolution," Nano Letters, vol. 13, no. 11, pp. 5585-5593, 2013.

[13] P. Guo, P. L. Ke, and A. Y. Wang, "Incorporated W roles on microstructure and properties of W-C: $\mathrm{H}$ films by a hybrid linear ion beam systems," Journal of Nanomaterials, vol. 2013, Article ID 530959, 9 pages, 2013.

[14] M. Weijers, F. van de Velde, A. Stijnman, A. van de Pijpekamp, and R. W. Visschers, "Structure and rheological properties of acid-induced egg white protein gels," Food Hydrocolloids, vol. 20, no. 2-3, pp. 146-159, 2006.

[15] M. Weijers, L. M. C. Sagis, C. Veerman, B. Sperber, and E. van der Linden, "Rheology and structure of ovalbumin gels at low $\mathrm{pH}$ and low ionic strength," Food Hydrocolloids, vol. 16, no. 3, pp. 269-276, 2002.

[16] E. van der Linden and L. M. C. Sagis, "Isotropic force percolation in protein gels," Langmuir, vol. 17, no. 19, pp. 5821-5824, 2001.

[17] C. Veerman, L. M. C. Sagis, J. Heck, and E. van der Linden, "Mesostructure of fibrillar bovine serum albumin gels," International Journal of Biological Macromolecules, vol. 31, no. 4-5, pp. 139-146, 2003.

[18] M. B. Dickerson, K. H. Sandhage, and R. R. Naik, "Protein- and peptide-directed syntheses of inorganic materials," Chemical Reviews, vol. 108, no. 11, pp. 4935-4978, 2008.

[19] G. Lang, Y. Kagiya, M. Ohnishi-Kameyama, and K. Kitta, "Evaluation of extraction solutions for biochemical analyses of the proteins in rice grains," Bioscience, Biotechnology and Biochemistry, vol. 77, no. 1, pp. 126-131, 2013.

[20] W. Chanput, C. Theerakulkait, and S. Nakai, "Antioxidative properties of partially purified barley hordein, rice bran protein fractions and their hydrolysates," Journal of Cereal Science, vol. 49, no. 3, pp. 422-428, 2009.

[21] Y. H. Zhang, C. H. Tang, Q. B. Wen, X. Yang, L. Li, and W. Deng, "Thermal aggregation and gelation of kidney bean (Phaseolus vulgaris L.) protein isolate at $\mathrm{pH} 2.0$ : influence of ionic strength," Food Hydrocolloids, vol. 24, no. 4, pp. 266-274, 2010.

[22] L. N. Arnaudov and R. de Vries, "Strong impact of ionic strength on the kinetics of fibrilar aggregation of bovine $\beta$ lactoglobulin," Biomacromolecules, vol. 7, no. 12, pp. 3490-3498, 2006.

[23] N. Kalashnyk, J. T. Nielsen, E. H. Nielsen et al., "Scanning tunneling microscopy reveals single-molecule insights into the selfassembly of amyloid fibrils," ACS Nano, vol. 6, no. 8, pp. 68826889, 2012.

[24] L. N. Arnaudov, R. de Vries, H. Ippel, and C. P. M. van Mierlo, "Multiple steps during the formation of $\beta$-lactoglobulin fibrils," Biomacromolecules, vol. 4, no. 6, pp. 1614-1622, 2003.

[25] C. H. Tang, S. S. Wang, and Q. R. Huang, "Improvement of heatinduced fibril assembly of soy $\beta$-conglycinin (7S Globulins) at pH 2.0 through electrostatic screening," Food Research International, vol. 46, no. 1, pp. 229-236, 2012.
[26] S. Ghosh, N. K. Pandey, S. Sen, D. R. Tripathy, and S. Dasgupta, "Binding of hen egg white lysozyme fibrils with nucleic acids," Journal of Photochemistry and Photobiology B: Biology, vol. 127, pp. 52-60, 2013.

[27] R. Eisert, L. Felau, and L. R. Brown, "Methods for enhancing the accuracy and reproducibility of Congo red and thioflavin T assays," Analytical Biochemistry, vol. 353, no. 1, pp. 144-146, 2006.

[28] R. Sabaté, I. Lascu, and S. J. Saupe, "On the binding of Thioflavin-T to HET-s amyloid fibrils assembled at pH2," Journal of Structural Biology, vol. 162, no. 3, pp. 387-396, 2008.

[29] P. Aymard, D. Durand, and T. Nicolai, "The effect of temperature and ionic strength on the dimerisation of $\beta$-lactoglobulin," International Journal of Biological Macromolecules, vol. 19, no. 3, pp. 213-221, 1996.

[30] X. H. Li, Y. H. Cheng, C. P. Yi, Y. F. Hua, C. Yang, and S. Cui, "Effect of ionic strength on the heat-induced soy protein aggregation and the phase separation of soy protein aggregate/ dextran mixtures," Food Hydrocolloids, vol. 23, no. 3, pp. 10151023, 2009.

[31] S. M. Kelly and N. C. Price, "The application of circular dichroism to studies of protein folding and unfolding," Biochimica et Biophysica Acta, vol. 1338, no. 2, pp. 161-185, 1997.

[32] M. Nakano, J. Shen, and K. Kamino, "Self-assembling peptide inspired by a barnacle underwater adhesive protein," Biomacromolecules, vol. 8, no. 6, pp. 1830-1835, 2007.

[33] S. Ikeda and V. J. Morris, "Fine-stranded and particulate aggregates of heat-denatured whey proteins visualized by atomic force microscopy," Biomacromolecules, vol. 3, no. 2, pp. 382-389, 2002.

[34] P. Matzinos and R. Álvarez, "Effect of ionic strength on rinsing and alkaline cleaning of ultrafiltration inorganic membranes fouled with whey proteins," Journal of Membrane Science, vol. 208, no. 1-2, pp. 23-30, 2002. 

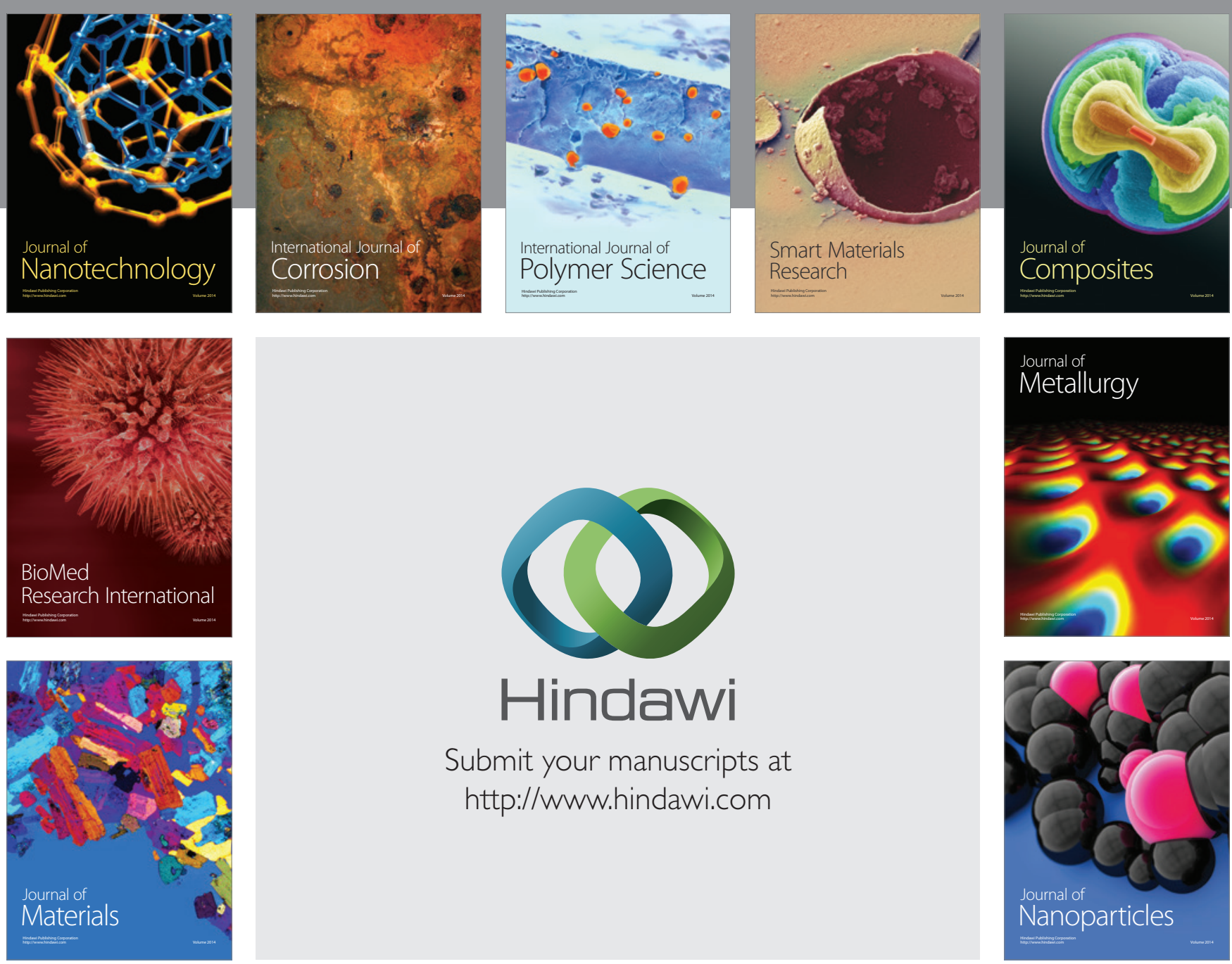

Submit your manuscripts at http://www.hindawi.com
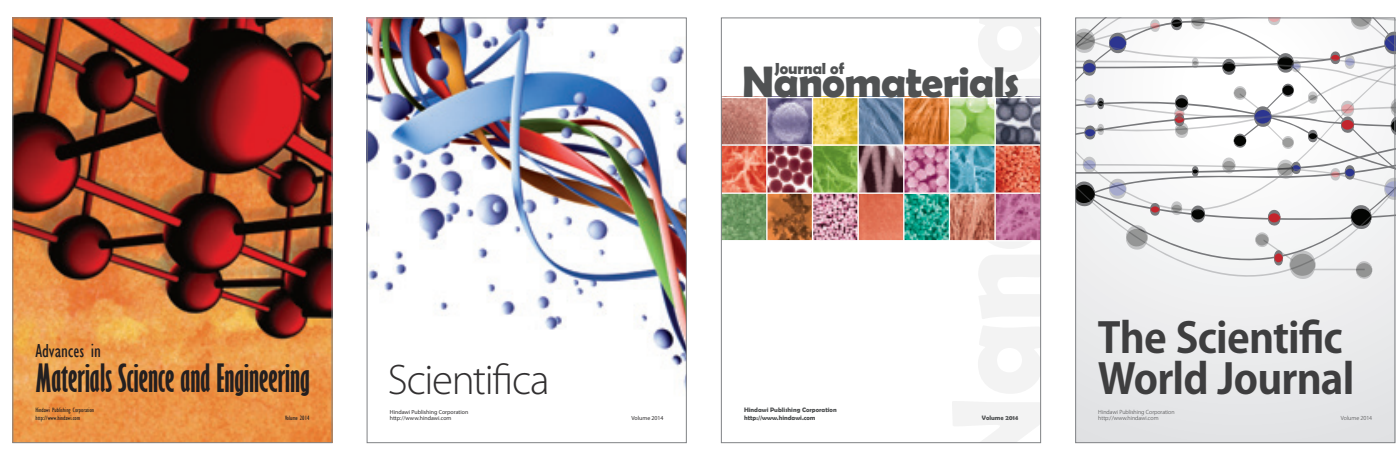

\section{The Scientific World Journal}
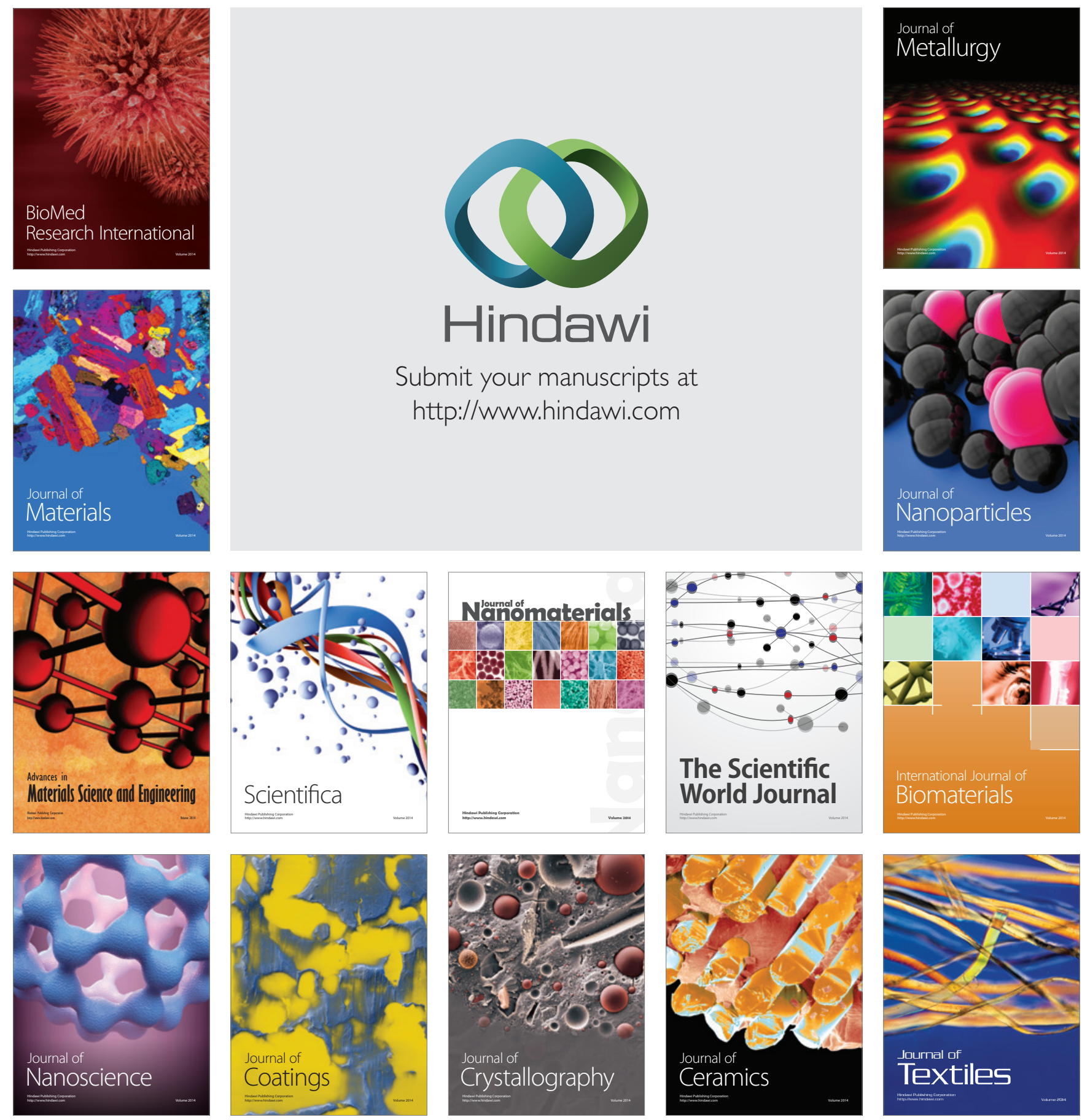